\title{
TO LECTURE OR DISCUSS? TEACHING NON- NATIVE ENGLISH SPEAKERS STUDYING INTERNATIONAL RELATIONS AT WEBSTER UNIVERSITY, THAILAND
}

\author{
Rachael M. Rudolph \\ Webster University, Thailand Campus
}

\begin{abstract}
Scholars have engaged the normative debates and contributed to the vast literature by focusing on the advantages and disadvantages of the didactic, student-centered and mixed-method approaches and their contribution to student achievement, motivation, performance and retention. Most of the studies conducted however, employ experimental and survey research methods thereby leaving qualitative case studies neglected. This is problematic because it is not possible to engage in a debate on how to implement teaching strategies and transform the classroom environment. This study qualitatively examines fifteen cases which have been taught by the author at Webster University's Thailand Campus in the Department of History, Political Science and International Relations between 2013 and 2018. Case selection was based on the teaching approach, the level of the course (1000 to 4000 level), and the temporal range. The breadth of the cases covered and the emphasis on how the strategies were implemented open the door to an academic discussion on how to transform the pedagogical approach employed. A discussion on transformation of pedagogy is important in the $21^{\text {st }}$ Century because of most primary, secondary and tertiary institutions are moving in the direction of adopting curricula and practices which are purely student-centered.
\end{abstract}

Keywords: Teaching Strategies, International Relations, Non-Native English Speakers, and Webster University Thailand

\section{Introduction}

Thailand is like many other countries across the world in requiring school curricula to be student-centered, yet the common practiced employed within the classroom at the primary, secondary and tertiary levels remains teacher-centered (Poohongthong and Supparerkchaisakul, 2017). Poohongthong and Suupparkchaisakul (2017) highlight that the discrepancy between requirements and practices are not just structural (i.e. time constraints, administrative duties, etc.), but also because of a lack of an emphasis on helping teacher's transform the teaching approaches they employ in the classroom. The transformation of teaching strategies does not seem to be focused on within the existing literature as well. Rather, there is a tendency for scholars to explore the debates between and benefits of the three teaching approaches, namely the didactic approach, the student learning centered approach, and the mixed method approach. To have a discussion on how to transform teachers' teaching strategies, there needs to be less debate within the literature on which approach best enhances students' achievement, motivation, performance and retention and more studies focusing on the implementation of teaching strategies within the classroom. There is needs to be more qualitative case studies within each of the disciplines so that academics and policymakers can ponder and discuss strategies for transformation from how teachers' implement their teaching strategies in the classroom.

This study seeks to contribute to the existing literature by focusing on the implementation of teaching strategies within selected courses taught to a primarily non-native English student population over a five-year teaching period in the Department of History, Political Science and International Relations at Webster University's Thailand Campus. Section one of this study provides an overview of the literature on teaching approaches and categorizes them according to each approach's normative assumptions, aims, teaching methods, and benefits 
and limitations. Section two outlines the methodological approach adopted. This study diverges from the existing literature by employing a purely qualitative case study approach and argues that a case study approach is needed for there to be a discussion on implementation and transformation. Section three systematically examines the selected cases according to the teaching approaches and discusses them in relation to the existing literature. Each sub-section concludes with a reflection on the lessons learned. Section four concludes the study by discussing implementation of the teaching approaches across the cases and in relation to transforming the learning environment for transforming teachers' individual pedagogical approaches in the classroom.

\section{The Didactic, Student-Centered and Mixed-Method Teaching Approaches: A Short Review of the Literature}

A teaching strategy is a deliberately selected plan of action that involves the use of methods, techniques and procedures which are flexibly applied by the teacher to accomplish the desired course outcomes (Mehigan, 2005, pp.557-558, Bhali and Asif, 2016, p.614). The existing literature primarily focuses on the two dominant teaching approaches, which are the didactic approach and the student learning-centered approach (Nagel, 2008, Sancho-Vinuesa, et. al., 2013, Johnson and Barrett, 2017). The didactic approach is teacher-centered and emphasizes lecture, whereas the student-centered or the learning-centered approach emphasizes teacher facilitation of a student-driven learning process. Only a few studies focus on what could be referred to as a mixed-methods approach (Rowe, 2016); that is, a strategy which employs a plan combining the methods and procedures from the two dominant teaching approaches. A lack of emphasis on the mixed method approach but a predominant focus on the didactic and learning-centered approaches in the literature means that, at least initially, only the normative assumptions, aims, methods and benefits and limitations of the two dominant approaches can be extrapolated.

Within the didactic approach, there are four overarching normative assumptions which are common among the referenced studies. First, the didactic approach is the dominant approach employed by teachers at all levels of teaching, which enhances students' motivation and thus performance through knowledge transfer. Second, the transfer of knowledge or, rather, providing a foundation of both knowledge and critical skills are necessary for the acquisition and development of higher levels of learning within the students' discipline. Third, lecture is an important mode of knowledge transfer and remains the most predominantly used teaching method among teachers. A didactic lecture is defined as "a constant oral presentation of facts with organized thoughts and ideas by a qualified person (Kumar, et. al., 2015, p. 1). As a method, it is considered economical, efficient, comprehensible, and needed for the timely completion of the syllabi and the teacher's other duties such as administrative or committee work, community service and research. Fourth, the transfer of knowledge through lecture is necessary for students' acquisition of a theoretical foundation for which they can understand and engage others within their discipline. The main aims of the didactic approach are to transfer knowledge to the students, to have students acquire and develop knowledge and critical skills, and to have students understand and engage their discipline. The cited teaching methods aside from the didactic lecture, which was already discussed, include Ted-ED talks or other public forum talks which are available online or through YouTube, chalk and board, PowerPoint, documentaries and video clips, animations, Quizlet, and Scoop.It (Kumar, et. al., 2015, Cudney and Ezzel, 2017). Kumar, et. al. (2015) highlight there is a lack of emphasis on the teaching methods employed in the didactic approach as well as the student-centered approach. Teachers who employ the didactic teaching approach posit that it provides a convenient, important and simplistic mode for the transfer of knowledge and does not require additional resources (Ijaz and Ul-haq, 2014, Cudney and Ezzel, 2017). Despite the preference for the approach and its predominant use, the referenced literature highlights that it promotes superficial learning as a result of the over-emphasis on rote memorization of facts, concepts and theories (Rowe, 2016), a student focus on passing rather than understanding course content (Poohongthong and Supparerkchaisakul, 2017), and limits constructive dialogue, thereby creating a dependent relationship between the student and teacher (Papworth, 2016). The studies focusing on student preferences varied, with some 
indicating a preference for the didactic approach over the student-centered approach and others preferring the latter over the former (Struyven, Dochy and Janssens, 2008).

Within the student-centered approach, there are four overarching normative assumptions. First, the generation of new ideas and creativity which is driven by students and facilitated or guided by the teacher creates an environment where there can be a greater transfer of knowledge. In a student-centered learning environment, students are introduced to and immerse themselves in the culture of their academic discipline. Second, students learn to develop trust and sharpen their cognitive and critical thinking skills through student-activating methods such as small group projects and task-oriented assignments. Third, the "student activating methods challenge students to construct knowledge by means of authentic assignments that literally require their active participation in the learning/teaching process to incorporate [and apply] the available information from external sources" (Shruyven, et. al., 2008, p.297). Fourth, teachers facilitate and guide the student-driven learning process by providing directional or instructional information which enables a greater transfer of knowledge. The main aims of the student-centered approach are to facilitate a student-driven learning centered environment, to guide the transfer of knowledge through directional instruction, to promote student achievement, motivation, performance, and retention, and to develop a sense of responsibility for the student-driven learning process. Student-centered teaching methods and aides are not really focused on within the existing literature. There are only references to small group, collaborative projects and reflection and exploration assignments and instruction provided by teachers (Nagel, 2008, Johnson and Barrett, 2017). Studies highlighting the benefits of the approach find that it increases student attention and thus cognition, achievement, motivation, retention, and decreases student dependency on the teacher for the transfer of knowledge (Nagel 2008). Poohongthong and Supparerkchaisakul (2017) find that structural factors such as overloading content into the curriculum, teaching overload, and the time spent for and lack of teacher training in the learning-centered approach hinder implementation and transformation of an individual's teaching strategy from the didactic to a learning-centered approach. An emphasis on implementation and transformation of teaching strategies are not really focused on in the existing literature, and this is problematic because of the overwhelming adoption of the learning-centered approach by academic institutions yet the continued use of and preference for the didactic approach by experienced teachers.

The mixed-method approach, as was previously highlighted, is not a primary focus within the existing literature. Rowe (2016) posits that there is a need for an integration of teaching strategies to provide students with the knowledge they need at all levels. As was highlighted in the literature on the didactic approach, lecture provides students with the foundational knowledge they need to engage in a higher-level of learning. A greater transfer of knowledge, as advocated by the student-centered approach, is not conceivable without a conceptual and theoretical foundation and instruction which teaches students how to engage and use the information they have acquired through lecture, readings and assignments. Moreover, teachers are not going to be able to transition from one approach to another without an understanding of and focus on how teaching strategies are limited. This study adds to the literature on mixed-method teaching approach by focusing on five courses wherein it was applied, contributing to an understanding of the normative assumptions, aims, methods and advantages and disadvantages of the approaches, and engaging the missing component of the debate on teaching strategies, namely on implementation and transformation of teaching strategies.

\section{Methodology}

This study adopts Katherine Riley Mehigan's Strategy Toolbox Model to discuss and examine the didactic, student-centered and mixed method teaching approaches employed in the selected cases. According to Mehigan (2005, pp.552-553), the model helps teachers to identify, adapt, modify and combine their own teaching strategies so that they can be shared and reflected on to promote individual and collective teacher development. By adopting the model, five assumptions frame the study's analysis (Meighan, 2005, p.556-564). First, teacher development begins at the individual level and by identifying, discussing, adapting and modifying teacher 
strategies. Through individual teacher development and discussion with others within and across the academic disciplines, both the discipline and the institution will likewise develop. Second, analyzing and discussing teacher strategies help teachers to view strategies and teacher-student engagement from different perspectives as well as gaining a better understanding and appreciation for how they can be applied. Teachers cannot develop if there is not a discussion on how to implement the different types of teaching strategies. Third, analyzing and discussing teacher strategies help individual teachers to understand strategies in relation to context and to better monitor how they impact students with different learning styles. Likewise, a deeper understanding of the different teaching strategies allows teachers, departments and institutions to develop better measurements for assessing teachers' successes and failures and student achievement and retention, as well as to determine the feasibility of a strategy's use within a given context and among certain student populations. Fourth, the analytical process of identifying teacher strategies is useful for teachers to develop more rigorous thinking about teaching. Finally, by sharing the strategies and how they are used help teachers by having not only a repertoire of teaching strategies, but also by providing examples of how those strategies can be implemented in the classroom.

The declarative, conditional and procedural questions which the Strategy Tool Box Model poses are as follows: 1) What is the strategy or set of strategies? 2) Why should they be used?, and 3) How do they work? These questions are asked for each course within the teachings approaches, for each teaching approach, and across the teaching approaches. By breaking down the analysis accordingly, the methods used in each course can be highlighted and discussed in relation to the debates in the existing literature. As the brief review of the literature highlighted, the existing studies tend to focus on the approaches and not per se the methods employed and how they were implemented. The methods are just as important as the teaching strategy. This study is, therefore, unique because it emphasizes the implementation of teaching strategies and methods within the selected courses rather than engaging in the debate on which strategy is better for enhancing student achievement, performance and retention.

\section{Strategies in Context: Employing Different Teaching Approaches within the Discipline of International Relations at Webster University's Thailand Campus}

Webster University Thailand's Department of History, Political Science and International Relations offers students studying in Cha-Am, Thailand a Bachelor of Arts degree in International Relations. The degree is accredited by the U.S. Department of Education and Thailand's Ministry of Education. Students who study in the program are primarily non-native English speakers from South and Southeast Asia. There are also students from Europe, Africa and America who study in the program, but they comprise the minority of the student population. As a result, each class consists of many different nationalities ranging from 17 to 35 who have varying educational, experiential, socioeconomic and sociopolitical backgrounds. Classes typically run for 16 weeks in the Spring and Fall semesters and for eight weeks in the Summer semester. The 16-week courses meet once per week for three hours, while the eight-week courses meet twice per week for three hours per session. They also ranged according to the level difficulty (1000 to 4000). The aims, objectives, teaching methods and course content including assigned reading materials and assignments are discussed within each of the course across the teaching approaches. Each sub-section concludes with a reflection on the lessons learned in relation to the referenced literature.

\section{The Didactic Teaching Approach}

The courses selected employing the didactic approach include INTL 1000: Introduction to Global Insurgencies (Spring 2014), POLT 3310: Conduct of Foreign Policy (Fall 2014), and INTL 4600: Asian Security: Antiterrorism and Counterterrorism (Summer 2014). Lecture was the primary teaching method employed, but it 
was supplemented by a minimum of three documentaries depending on the course and the use of social media platforms such as Facebook and the author's personal blog. ${ }^{1}$ Assignments were distributed throughout the sixteen weeks and used to assess students' understanding of the lecture content. Modifications were made as needed and according to whether the students understood what had been previously delivered in the lecture. Each course is examined separately throughout this sub-section.

In the Introduction to Global Insurgency course, the main aim was to introduce students the contemporary understanding of insurgency and counterinsurgency within the context of selected insurgencies. ${ }^{2}$ The course objectives were as follows:

- To learn of the complexity of the environment where insurgencies occur;

- To learn of the prerequisites, fundamentals and threat characteristics of insurgencies;

- To learn of and develop an understanding for the shared commonalities of insurgencies across the globe;

- To learn how to critically examine a specific phenomenon;

- To learn how to conduct research and articulate arguments orally and in writing; and,

- To develop critical communication and writing skills.

The insurgencies selected included the Boko Haram insurgency in Nigeria, the Katanga insurgency in the Democratic Republic of the Congo, the Houthi insurgency in Yemen, the Chechen insurgency in Chechnya, the Afghan insurgency in Afghanistan, the insurgencies in the Northeast of India, the Southern Insurgency in the South of Thailand, the Communist insurgency in the Philippines, the FARC insurgency in Colombia, the Paraguyan insurgency in Paraguay, the Kurdish insurgency in Turkey, the ethnic insurgencies in Myanmar, and the insurgency in Syria. Each student was randomly assigned an insurgency to research. Lecture was used to provide students with a basic understanding of the definitions, concepts and theories, and an analytical framework to analyze the strategic context and operational environment, culture, the prerequisites and fundamentals of insurgency, and strategies and tactics employed by the insurgents. Documentaries supplemented the lecture to mediate the theoretical and conceptual nature of the lecture content. Homework assignments were distributed across the course to reduce the research burden at the end of the course and as a tool to assess the students' understanding of the lecture content. The reading materials assigned ranged from the U.S. and UK military manuals on insurgency and counterinsurgency and scholarly works published by preeminent military science scholars. Discussion was limited to the days when the documentaries were watched and on the due date of homework assignments.

\footnotetext{
${ }^{1}$ Each course has its own Facebook page. The albums contain course documents and lectures. Mental2Musings is the blog I use to post lecture for my courses. I began using the blog in addition to Facebook because of some of the students not using the platform. All course documents and lectures are also uploaded to the World Classroom platform which Webster University uses to manage the courses taught across the globe at each of the campuses.

2 The link to this course's Facebook page is as follows:


In the Conduct of Foreign Policy course, the aims were to study the foreign policy decision-making process by studying the actors, the decision environment and the types of decisions made, and to learn the different theoretical and game-theoretic lenses which can shape actors' decisions and how they can influence the types of decision which emerge within a given decision environment. ${ }^{3}$ Students examined the foreign policy decisionmaking process within the context of Myanmar, looking more specifically at how the foreign policy of key strategic actors could be network to help facilitate peacebuilding in the state. The course objectives were as follows:

- To develop an understanding of foreign policy and how the actors influence the foreign policy decision-making process;

- To examine the role and importance of context for foreign policy’

- To understand the impact of foreign policies on facilitating coordination and cooperation among state and non-state actors for peace-building.

Lecture was the primary teaching method used to deliver the conceptual and theoretical content needed to understand the foreign policy decision-making process. Documentaries were used to provide a background on the conflict in Myanmar. A core text was used to supplement the lecture content. In addition, students were required to read academic studies and government reports on both the conflict in Myanmar and the foreign policies of the two states they were assigned to research for the first course assignment. The assignments for the course consisted of two extensive research papers and presentations. In the first research assignment, each student had to research the foreign policies of two states which were deemed strategically significant to Myanmar's ethnic insurgency and present the findings to the class. In the second assignment, students were paired into seven groups. Each group was responsible for a specific ethnic state within Myanmar. They were required to develop strategies for peacebuilding from the assigned state's perspective, taking into consideration the actors within the state and across the states of Myanmar and the foreign policies of the key strategic actors. The groups produced a research paper and delivered a presentation to the class.

In the Asian Security course, the aim was to have students engage in an in-depth study of antiterrorism and counterterrorism in Asia but in relation to the region's desire to create a common security framework to promote peace and stability. ${ }^{4}$ The main objectives of the course were as follows:

- To learn and examine the three AT/CT pillars, namely combating violence/terrorism through security and public diplomacy; combating violence/terrorism through the AML/CTF System; and, combating violence/terrorism through ideological, intellectual and cyber initiatives;

- To learn of ASEAN's AT/CT Approach and the importance of collective security among community members for promoting peace and stability;

- To conduct in-depth AT/CT research on selected ASEAN, EAS and SARC members states; and,

\footnotetext{
3 This course's Facebook page is as follows: https://www.facebook.com/conductofforeignpolicy/. The COF course runs every fall and the course content changes with each course. Please be sure to look at the albums corresponding to the year of reference.

4 This course's Facebook page is as follows: https://www.facebook.com/Exploring-News-and-Policies-in-Asia1464923523723679/.
} 
- To write on a specific AT/CT issues such as security, intelligence, public diplomacy, and/or retributive and rehabilitative justice.

Lecture was the primary teaching method. The materials assigned for the course included the author's book on the Saudi anti-terrorism and counterterrorism model, which details Saudi security strategy, policies and operations undertaken by the Saudi Ministry of Interior between 2003 and 2012, open-source books on the U.S. and U.K. antiterrorism and counterterrorism models including the U.S. military's manual on counterterrorism operations, regional member states' government documents on counterterrorism and security policy, and expert studies on the selected countries' security and counterterrorism policies. Students were taught through lecture and the assigned readings the existing counterterrorism models and how to conduct open-source intelligence analysis. They used open-source intelligence methods and an analytical framework, which the author was developing at the time, for their course research assignments. A total of four research assignments were given in the eight-week period, which meant that students spent many hours outside of the actual course contact time. The first assignment required students to conduct wire assessments to identify and analyze patterns of violent and non-violent behavior in two assigned regional countries. In the second assignment, the intelligence and security infrastructure and the security policies of the two assigned countries were assessed. The third assignment required students to write an annotated bibliography and a literature review on counterterrorism. The last assignment, which was a research paper on counterterrorism in the two selected countries, built on and used all the material produced in the previous assignments and what was delivered in lecture.

Upon reflection, there are several lessons which can be learned from using the didactic approach within the context of this study. First, the didactic approach is necessary to provide students with the foundation needed to engage in higher levels of learning. This is especially the case for non-native English speakers who are studying international relations in an English-based curriculum. The varying levels of English proficiency and comprehension require the teacher to provide and explain in detail the conceptual and analytical foundation of each subject and how they are to be used for analysis in order for them to engage the upper-level courses. The upper-level courses highlighted here could not have been taught in such a complex, strategic manner if the students did not have the foundation which was set forth in the lower-level courses. Second, the teaching methods used matter. Lectures were provided to students in PDF and PPT format and posted on Facebook, the blog and World Classroom prior to the start of class. Providing the lecture ahead of time was useful because it allowed students to ask questions on content they did not understand. They also knew which of the assigned reading material was more relevant, thereby allowing them to spend more time on specific articles or chapters. Third, the didactic lecture is beneficial for a teacher who is teaching a subject for the first time. Through lecture and observation of how the students respond to different points as it is being delivered, the teacher is able to gain an understanding of which material needs to be explained better or elaborated on for greater understanding. Fourth, there is not much of an emphasis on course content when discussing the teaching approaches, yet it is needed. What was learned from reflecting on the introductory and upper-level courses is that there was a tendency to try to cover too much content in a short period of time, and this could be the reason for students' superficial learning of a subject matter. In the upper-level courses, it was not so much an issue of course content as much as it was the assignments. Finally, assignments are also not focused on in the existing literature. The assignments in the upper-level courses were complex and the students did a commendable job, but there was mental fatigue toward the send of the semester by both the students and the teacher. Too many assignments could also be contributing to superficial learning of the subject matter.

\section{The Student-Centered Teaching Approach}

The courses selected employing the student-centered approach include HIST 1010: Street Art and Politics (Summer 2016), POLT 2060: Politics and Gender (Spring 2017), and POLT 2070: Race and Ethnicity (Spring 2018). Lecture was used to provide instruction and explanation for student-focused group projects or learningcentered group work. Group projects and group work were the primary teaching aides used for each course, but 
they varied in complexity according to the level of the course and its aims, objectives and content. Each course is examined separately throughout this sub-section.

In the Street Art and Politics course, the aims were to have the students explore the beauty and complexity of the politics and symbolism behind graffiti and street art by looking at them through the eyes of graffiti writers, street artists, cultural activists, the state and security apparatus, and the public; to participate in a graffiti and street art workshop led by a Thai graffiti writer and street artist; and, to design, prepare and implement a student-led graffiti and street art project on one of the campus buildings. ${ }^{5}$ The course objectives were as follows:

- To learn of the debates behind the terms street art or graffiti art.

- To learn of the different types of street art and graffiti, as well as some well-known artists within the U.S. and across the globe.

- To learn of the politics and symbolism laden in the street art and graffiti and how each one tells a story of given time, place and person.

Lecture was used to provide background information, guidance and instruction. Typically, the first one hour of the course was spent on lecture while the remaining two hours were spent either in discussion or group work. Students led the group work while the teacher walked around listening to the group discussion and answering questions and facilitating cooperation and exchange between the groups. The lecture component of the course only lasted for the first two weeks of the eight-week session. Weeks three and four were led by student discussion on the graffiti writers and street artists which the students had researched. On week five, the students were divided into two groups to plan for and map out their graffiti and street art murals. They needed to have an idea and sketch of the murals for the workshop. A Thai graffiti writer and street artist delivered a graffiti and street art workshop on week six. He also assessed the plans the students had drawn up the previous week. Week seven was spent making stencils and laying out the work for the murals as was instructed during the workshop. The students, teacher and graffiti writer/street artists came in on the weekend of week seven to prep the walls and spray paint the murals on the campus building. ${ }^{6}$ The class met on week eight to discuss the meaning, symbolism and politics behind the murals and what was learned over the course regarding theory versus practice. The course materials assigned included two books on graffiti and street art, selected chapters from a book on cultural activism, and documentaries on the psychology and symbolism of colors and the use art therapy to heal individuals suffering from post-traumatic stress disorder (PTSD) and communities suffering from violence. Course assignments consisted primarily of in-class assignments, a comparative research paper on graffiti writers and street artists, and a reflection paper on the meaning and politics of the student projects. The students had to critically analyze the murals with what was taught in lecture over the course of the semester.

\footnotetext{
5 This course's Facebook page is as follows: https://www.facebook.com/Exploring-Street-Art-and-Politics$\underline{1766648196892069 / .}$

${ }^{6}$ Photos of the workshop, student preparation and the final projects are available by clicking on the following link: https://www.facebook.com/pg/Exploring-Street-Art-and-Politics$\underline{1766648196892069 / \text { photos/?tab=album\&album_id=1817300195160202. }}$.
} 
In the Spring 2017 Politics and Gender course, the aim was to explore the main concepts and theories that seek to explain the role women play in intelligence, drug trafficking and organized crime, terrorism, and war and peace. ${ }^{7}$ The course objectives were as follows:

- To provide students with a conceptual and theoretical framework for analyzing the relationship of women in culture, society and politics;

- To understand how the relationship impact women differently across culture, society and the state; and,

- To examine specific aspects of the relationship within each of the specified areas.

The first three weeks of the course covered the concepts, definitions and theories through lecture and discussion. Rather than lecturing continuously and keeping in mind what students had struggled with when the course was taught using the didactic approach in 2014, questions were asked to engage the students and to try to elicit their own personal stories so that they could be connected to how a particular theory explained outcomes. Then, the students were required to use the theories to explain some aspect of the book on the life of Gail Harris, the first African American naval intelligence office. Two weeks of class were used to engage and discuss the book. Afterward, the students were split into groups and assigned chapters to read in the remaining three books, one on women drug traffickers, one on women as terrorists, and one on Muslim women in war and crisis. The method was similar in that they had to read the assigned chapters and analyze them through one of more of the theories taught in the first part of the class. Course assignments consisted of an in-class exam on the Gail Harris' book, a short research paper analyzing the book with the theories, and three group presentations.

In the Race and Ethnicity course, the aims were to provide students with an understanding of what is meant by race-thinking, race and racism, explore the politics of exclusion, situate race and its debates within the larger context of ethnicity and culture, and examine the varying theories used within academia to explain race and ethnicity but within the context of white and black nationalism. ${ }^{8}$ The main course objectives were as follows:

- To develop an understanding of race and ethnicity;

- To learn of the different conceptual and theoretical lenses to examine issues of race and ethnicity; and,

- To explore selected texts and figures pivotal to racial and/or ethnic tensions in the past and present.

The first three weeks of the course were spent examining the concepts of race, ethnicity and nationalism and theories on identity construction. Unlike the previous courses, lecture was not used to provide the conceptual and theoretical background. Each group of students was assigned selected articles on the topics and required to present on them informally (without using PPT). The presentations had to address a common list of questions, which had been given on the first day of class and was to be used for all the course readings. The remainder of the semester continued in this format, with the groups covering the remaining selected text. Hitler and Mein Kampf, Sophie Scholl and the White Rose Movement, Malcom X and his writings, and Bobby Seale and his book on the Black Panthers were covered. Other materials had been included, but in the second part of the

${ }^{8}$ The course's Facebook page can be accessed via the following link: https://www.facebook.com/ExploringRace-Ethnicity-378258242353065/.

${ }^{8}$ The course's Facebook page can be accessed via the following link: https://www.facebook.com/ExploringRace-Ethnicity-378258242353065/. 
semester the schedule had to be amended to reduce the reading content. The reading materials were not difficult for the students but because of how much engagement there was on Hitler, Mein Kampf and the White Rose Movement, it was better to reduce the course content. It should be noted that this was the first class in the author's entire teaching career where there was such a high-level critical engagement of the course content. ${ }^{9}$ Course assignments consisted of in-class assignments, class participation, a research paper and presentation, and a comprehensive in-class final exam.

Upon reflection, there are several lessons which can be learned from using the student-centered teaching approach. First, the generation of new and creative ideas which are driven by students and facilitated or guided by the teacher and the ability of the students to learn to develop trust and to sharpen their cognitive and critical thinking skills (the first two assumptions of the learning-centered approach) depend on the nature of the course content and the structure of course assignments. Too much content contributes to superficial learning, while too little content can lead to disinterest and demotivation. The key is to find a balance, even if it requires the reduction of the original course content. Similarly, too many course assignments can contribute to mental fatigue for both the teacher and the students, which thus has an impact on group-projects and simulations. Additional research on course content and course assignments is needed to better engage the debates within the literature on teaching strategies. Second, students need a foundation in the subject area in order to engage at a higher-level, but when it is provided and combined with a student-centered approach in the lower-level courses, they are able to engage at a deeper level in the upper-level courses. Again, either finding a balance between lecture (whether traditional or instructional) and student-activating teaching methods or developing course assignments which facilitate the students' learning of the basic concepts, definitions and theories (e.g. the Race and Ethnicity course) is necessary to facilitate a higher-level of learning and student-to-student transfer of knowledge. Third, there needs to be more of a focus on the different types of student-centered learning methods in order to better understand the assumptions of the student-centered learning approach. The three different types of methods employed in the selected cases can be categorized according to student-guided transfer of knowledge methods (e.g. the use of books and group presentations), a research driven methods approach (e.g. sharing of responsibility), and task-oriented or assignment driven method (e.g. use of simulations). Methods, as will be recalled from the assumptions identified from the existing literature on the student-centered learning approach, challenge students to construct knowledge. They, therefore, should vary in complexity and according to the type of learning environment the teacher is attempting to facilitate. A teacher must be cognizant of the type of environment s/he wants to create and of the different types of methods which can be employed to accommodate the varying student learning styles.

\section{The Mixed Method Teaching Approach}

The courses selected employing this approach include POLT 3310: Conduct of Foreign Policy (2015 and 2017), and KEYS 4003: Human Trafficking (2015 and 2017). Each course is discussed separately in this sub-section. The Conduct of Foreign Policy and the Human Trafficking courses are being counted twice because of the changes in the format, content and the types of methods employed. This sub-section concludes with reflections on implementation of the mixed-method within the context of the courses taught and in relation to the assumptions identified from the existing literature.

In the Conduct of Foreign Policy courses, the aims and objectives were similar to those which were discussed when the course was taught in 2014 using the didactic approach but differed according to the focus and the teaching approach and methods employed. The 2015 and the 2017 courses discussed here were also different by focus and the methods despite utilizing the mixed-method approach. In 2015, the course focused on foreign

\footnotetext{
${ }^{9}$ The author started teaching at the university level in 2005.
} 
policy decision-making process and the Afghan insurgency. The foreign policy decision-making process was covered in the first eight weeks of the course through lecture. Lecture was supplemented with a core text on the decision-making process. Students also had to simultaneously read a book on the culture, history and politics of Afghanistan and a U.K. Ministry of Defense report on tribal and ethnic cleavages. The aim in the first part of the course was to provide students with a foundation upon which they could build in the simulation in the second part of the course. In simulation, students were divided into groups according to Afghanistan's regional divisions, and each group was assigned key strategic provinces to assess. The purposes of the simulation were to assess the internal and external actors and their issues and interests in both the continuation and end of the Afghan insurgency and to develop proposed strategies for networking the external actors' foreign policies in order to implement networked stability operations. Students were required to conduct in-depth research on Afghanistan and brief the class each week over an eight-week period on the tasks assigned. In the last week of the simulation, the entire class discussed and shared ideas on how to develop a strategic doctrine to wage network stability operations in Afghanistan. Course assignments consisted of an in-depth research paper on the foreign policy decision-making process in two countries, five simulation task assignments, two major briefings, and one strategy paper on strategies for implementing network stability operations. In the 2017 foreign policy course, the focus was on foreign policy decision-making and North Korea. A foundation in the foreign policy decision-making process was provided in the first six weeks of the course through lecture, while the remainder of the course was spent on student-activating methods including discussing the selected books on North Korea, student research papers, and how to facilitate cooperation among the actors in the global informal and illicit economies for peace-building initiatives. A simulation was not run because of the small number of students enrolled. Instead, the second part of the course operated more like a seminar where each student was responsible for contributing to a certain part of the discussion. Course assignments consisted of an in-class midterm exam on the foreign policy decision-making process, writing a literature review and an in-depth research paper, and class participation.

In the Human Trafficking courses, the aim was to provide students with an understanding of the global phenomenon of human trafficking, human trafficking victim narratives, the impact of human trafficking within specific countries and regions, and the approaches to combating and preventing human trafficking. ${ }^{10}$

- To explore human trafficking globally and within specific regions and countries;

- To highlight the conceptual fuzziness between human trafficking, smuggling and migration and the different international, regional and nation-specific definitions given to the concepts;

- To understand the national, regional and international legal gaps and how they impact efforts to combat and prevent trafficking globally, regionally and nationally;

- To investigate human trafficking in a selected region and/or country; and,

- To develop an awareness video or alternative production which brings global, regional and/or domestic awareness to human trafficking.

10 The course's Facebook page can be accessed with the following link: https://web.facebook.com/exploringtrafficking/?ref=br_rs. An album exists for each year the course was taught. Student work including awareness videos on trafficking can also be found in the page tables. The videos are also accessible through the author's YouTube page. 
Despite the aims and objectives of the courses being similar and them both being taught within the mixed method teaching approach, the focus and teaching methods varied. In the 2015 human trafficking course, the students focused on human trafficking in the United States and Thailand. This year was the first time the course was taught, and it ran at the same time the Thai government was implementing new strategies to remove itself from the U.S. Trafficking in Persons Tier 3 ranking. Students looked at trafficking in Thailand in relation to the U.S. and engaged in two significant projects, namely conducting interviews with local, regional and global NGOs and/or government officials on human trafficking and producing two awareness videos to bring attention to sex and labor trafficking in Thailand. They also produced a research paper which looked human trafficking as understood in the present in relation to slavery as understood in the past. The teaching methods included didactic and instructional lectures and documentaries and student-activating methods such as group presentations, fieldwork, and video production. Lectures were delivered over the course of the 16 weeks. In the 2017 human trafficking course, the students focused on human trafficking in the Mekong region. The course ran at the same time the U.N.ACT in Bangkok was preparing a regional report on trafficking in the Mekong region. Rather than spreading the lectures across the 16 weeks as had been done previously, the first four weeks of the course were spent laying the conceptual and legal foundation of the subject and how it was understood within the context of the Mekong countries. Lecture provided students with the framework for examining the countries while they undertook group-based research tasks to examine human trafficking in specific countries. Each group was assigned one Mekong country, which was focused on over the course of the 16 weeks. As they learned about the definition problem and the legal differences through lecture, the groups conducted research on the same thing within the assigned country. This approach was applied through the course and, in so doing, the students produced extensive country reports at the end of the semester. In addition, the students produced videos on human trafficking. The students utilized real trafficking narratives which they found from the U.S. TIP Reports, country government reports and/or media reports to create fictionalized narratives that were acted out to bring awareness to human trafficking narratives. Human trafficking narratives were the main focus because this remained one of the main issue areas of critique for the Thai government by the U.S. in the TIP Report. The methods were similar as what had been employed in the 2015 course but they different in that there was a greater emphasis on instructional lecture and student-activating methods. Course assignments were also reduced in the 2017 course. The students were overworked in the 2015 course.

Upon reflection, there are several lessons which can be learned from employing the mixed-method approach. First, the mixed-method approach became the author's preferred approach in the post-2015 period. It was also in this period when the courses began to rotate and new methods, assignments and material could be cycled in and others omitted based upon reflection of how the courses were previously taught. Second, the didactic approach was necessary for the author to employ in the first two years of teaching because of not being familiar with the students and needing to write course preps. Third, there was more student participation and teacher motivation in the mixed-method approach than when simply employing the student-centered approach. The students were more confident to engage one another and the teacher because of the foundation provided through the didactic lecture. The only exception was the Spring 2018 Race and Ethnicity course. Student engagement was higher than in any previous course and the level of analytical engagement was far more expansive in terms of the number of students' participating than in the upper-level courses which were taught in didactic approach. There were a lot of students enrolled in that course who came to Thailand from Webster's Leiden and St. Louis campuses for the semester. This course could be an outlier. Finally, the level of student engagement depends not just on the course methods but also the course reading materials and assignments. Additional studies should be conducted to better understand how the selected reading materials and course assignments impact the teaching approaches and student engagement, performance and retention.

\section{Conclusion}

This study employed Meighan's Strategy Toolbox Model to examine the implementation of selected courses within each of the didactic, student-centered and mixed-method teaching approaches. As was highlighted in the 
literature, implementation of the teaching approaches is not something which is typically focused on by scholars. This is problematic because it is from a discussion on how the teaching approaches are implemented which will help teachers improve their pedagogy. By learning from one another, we can try new things to increase student engagement and student-teacher interaction within the classroom as well as reduce the time spent on preparing didactic lectures. There would be additional time for research and other administrative tasks.

A focus on implementation of teaching strategies would also provide rich in-depth case studies from which we can draw lessons from to develop strategies or teacher development programs to help teachers transition from the didactic teaching approach to the student-centered approach or the mixed-method approach. Academic studies on the transition process are necessary because of more primary, secondary and tertiary schools requiring programs, departments and teachers to employ a student-centered approach. Teachers who have been predominantly employing the didactic teaching approach cannot simply switch to a different teaching approach overnight regardless of the teachers' experience. As the existing literature highlights, more experienced teachers prefer the didactic approach over that of the student-centered approach (Cayirdag, 2017). A transitionary strategy which facilitates the gradual transition from didactic to mixed-method to student-centered may help to better transition programs, departments and schools and reduce the hostility among the older teachers who are hesitant to adopting different teaching methods in the classroom. It may also enhance the transformation of the learning environment. As the existing literature highlights, the transformation of the teaching environment depends quite a bit on student engagement and participation. It also depends on teacher engagement. Too many of the existing studies focus on the student component rather than on the teacher.

For teachers to guide students to the doors which enhance knowledge transfer, there needs to be more attention given to implementation and transition of teachers' pedagogical approaches and practices and more discussion among teachers within the existing literature. Discussion is rich in conferences, but it is lacking in the literature due to our over emphasis on quantitative and mixed-methodological approaches to the study of teaching strategies. All teachers who entered the profession did so, in part, because of the belief in the power and importance of education to transform individuals and society. Shall we believe in the power and importance of the pen to transform us as teachers so that we can better help our students to realize their full knowledge potential?

\section{References}

Bhali, MA, Sattar, A, and Asif M., 2016, Teaching Strategies: Perception of Medical Students, used in basic sciences years. The Professional Medical Journal, 23(5), 614-619. DOI: 10.17957/TPMJ/16.3206

Cayirdag, N., 2017, Creativity Fostering Teaching: Impact of Creative Self-efficacy and Teacher Efficacy. Educational Sciences: Theory \& Practice, 17(6), 959-1975. DOI 10.12738/esp2017.6.0437

Cudney, E.A. and Ezzel, J.M., 2017, Evaluating the Impact of Teach Methods on Student Motivations. Journal of STEM Education, 18(1), 32-48.

Ijaz, A. and Ul-haq, S., 2014, Evaluation of Strategies to Increase Students' Involvement for Improving Interactive Lecture in Chemical Pathology. Pakistan Armed Forces Medical Journal, 64(2), 237-43.

Johnson, H.A. and Barrett, L.C., 2017, Your teaching strategy matters: how engagement impacts in health information literacy instruction. Research Communication, 105(1), 44-48.

Kumar, M., Saxena, I., Kumar, J., Kumar, G., and Kapoor, S., 2015, Assessment of Lecture Strategy with Different Teaching Aids. Journal of Clinical and Diagnostic Research, 9(1), 1-5. DOI: 10.7860/JCDR/2015/10805.5413

Mehigan, K.R., 2005, The Strategy Toolbox: A ladder to strategic teaching. The Reading Teacher, 58(6), 552566.

Nagel, P., 2008, Moving Beyond Lecture: Cooperative Learning and the Secondary Social Studies Classroom. Education, 128(3), 363-368. 
Papworth, R., 2016, A Multi-disciplinary, Social Constructivist Approach to Promoting Student Engagement, Retention, and Achievement in Higher Education. Dialogue Book: 1-17. Available at : http://dlib.eacademy.bg/bitstream/handle/10610/3146/p592_DialogueBook3eng2016 52_68.pdf?sequence=1\& isAllowed=y

Poohongthong, C. and Supparerkchaisakul, N., 2017, Designing Learner-centered Instruction Practices Based on Transformative Learning through Critical Participatory Action Research. International Journal of Behavioral Science, 12(2): 31-49.

Ramierz, H. and Jones, D., 2013, Effects of Reading Strategies and the Writing Process with Written Recasts on Second Language Achievement, Administrative Issues Journal: Education, Practices, and Research, 3(1), 7385. DOI: $10.5929 / 2013.3 .1 .7$

Rowe, M., 2016, Beyond the lecture: Teaching for professional development. African Journal of Health Professions Education, 8(2), 208-210.

Sancho-Vinuesa, T., Escudero-Viladoms, N., and Masia, R., 2013, Continuous activity with immediate feedback: a good strategy to guarantee student engagement with the course. Open Learning, 28(1), 51-66.

Struyven, K., Dochy, F., and Janssens, S., 2008, Students' likes and dislikes regarding student-activating and lecture-based educational settings: Consequences for students' perceptions of the learning environment, student learning and performance. European Journal of Psychology of Education, 23(3), 295-317. 